\title{
The Value and Risk of Curated Shopping: Online Consumer's Choice
}

\author{
Hoon S. Cha \\ Information \& Decision Sciences \\ Perdue School of Business \\ Salisbury University \\ hscha@salisbury.edu
}

\author{
Soeun You \\ Department of Business Administration \\ MBNA School of Business and Accounting \\ Wesley College \\ soeun.you@wesley.edu
}

\begin{abstract}
The rapidly increasing number of products available online ironically requires consumers to spend excessive time and efforts for searching the relevant product information. As a result, it is getting popular among online consumers to use the curated shopping, which can help consumers by providing a short list of products that are carefully selected by professional curators. In this study, we examined how the risk and value of curated shopping perceived by consumers affect their decision to use the curated shopping. Through empirical analysis, we found that the perceived convenience, efficiency of curated shopping, and the degree of shopping fatigue as positive factors that increase the intention to use curated shopping. On the other hand, the perceived financial risk was found to be a significant negative factor. Furthermore, it was interesting to find that previous experience of curated shopping acts as a moderator, which affect the strength of the above relationships. The academic and practical implications of these findings were discussed.
\end{abstract}

\section{Introduction}

Online shopping is attractive as consumers can search relevant product information faster and easier, and make purchase decisions more conveniently and inexpensively than offline shopping. However, this may not be always true as the information overload has become a serious issue with the rapidly increasing number of products sold through online stores and with the availability of new information sources such as various social media. As a result, it is getting popular among online consumers to use the curated shopping, which can help consumers by recommending a limited number of selected products rather than over-feeding superfluous product information.

Curation is not a new phenomenon but for a long time, museums and galleries have been relying on professional curators to select unique items for collection and display. However, recently curation has begun to see wider applications in a variety of online content services as it allows users to accelerate the process of discovering relevant information and cut down the time they spend screening out unwanted contents. The early online curation services, like the well-known Pinterest (pinterest.com), allow users to find useful information among various web contents such as news, images, videos, etc. and collect them on a personal bulletin board (i.e., pinning). After then, those contents are reorganized according to personal preferences (i.e., re-pinning) and shared with other users. This process is often called as social curation as the contents are selected and shared among social network users. The social curation process enables users to add their qualitative judgment (either like or dislike) to indiscreet web contents, and as a result, the value-added web contents could be re-shared among other users who have common interests [27]. Pinterest started its official service in May 2011, then it has reached 11 million subscribers in January 2012, which is the fastest grasp of 10 million users in Internet service history. In July 2013, the number of subscribers exceeded 70 million [4] and has crossed the big line of 100 million users in 2015. As shown in the example of Pinterest, the role of curation has become more important than ever as web contents have increased exponentially and thus it becomes more difficult to find desired information. In the flood of big data and given the limited information processing ability of human, people became more interested in the prefiltered information that had been ranked by their acquaintances or experts.

While social curation mainly focused on services such as filtering and scrapping web contents, curation service has been naturally expanding its scope to online shopping where the similar concepts are applied for the product information. Many online consumers feel that it is very cumbersome to search for and compare the tens of thousands of products and relevant information infused from existing shopping malls, open markets, search engines, and social media. Curated shopping is targeting those exhausted 
consumers. The product information of various items is filtered based on the recommendation of friends in the social networks, professional curators, or tastemakers (such as famous actors or actresses) they follow.

One of the curated service models is to display and sell goods which are curated by professionals or experts. One popular example is Fab (Fab.com) that displays and sells goods such as furniture, kitchen items, costumes, and shoes that are carefully curated by professional designers. 6PM (6pm.com) is another curated shopping portal that offers retail shoes, clothing, bags, accessories, and more for women, men, girls, and boys. Other examples include, Wanderfly (wanderfly.com) that had curated travel goods (now sold to TripAdvisor). In addition, the Web giant Amazon (Amazon.com) has launched MyHabit in 2011 as a private fashion site that offers handpicked selections from designer and boutique brands, which is now merged with ShopBop that was also acquired by Amazon.com.

Another model of the curated shopping focuses on the personalized service. For example, Truck Club(trunkclub.com) owned by Nordstrom, and MM.Lafleur (mmlafleur.com) Bento offer the service to send stylist handpicked clothing to the customer based on customers' preference.

The subscription is also one of types in curated service. Wine Awesomeness(wineawesomeness.com) provide new wines every month with a curated set of bottles and a customized magazine to their membership customers. Another subscription service is Birchbox(birchbox.com) which give five beauty products based on your beauty preference with $\$ 10$ monthly subscription fee.

As shown in the examples above, curated shopping provides consumers the great benefits of providing the desired shopping information more concisely, conveniently and quickly than traditional online shopping malls through the light and intuitive platform. On the other hand, there are also criticisms against curated shopping that it cannot sufficiently reflect the purchasing intention of consumers as the curator is in charge of actual search and comparison of the products on behalf of customers. With the lack of full control of purchase decision making, consumers may perceive higher levels of risk and uncertainty that have been broadly studied in the previous literature [10, 12, 23]. Given these mixtures of advantages and disadvantages of the curated shopping, we do not expect that the curated shopping will completely replace the traditional online shopping malls. Instead, both curated and traditional online shopping malls may coexist for a while, complementing each other.

When the traditional and curated online shopping malls exist together, the purchase decision process of the consumers is getting complicated as they need additional step of choosing the better buying option. Of course, the greater the benefits and advantages of curated shopping with the less awareness of the risk, the higher the probability of choosing curated shopping. In addition, the difference in each consumer's personal characteristics may be also important factors in choosing between these two types of shopping options. For example, some consumers who feel easily tired of excessive information will prefer the curated shopping despite of the inherent risk factors. In contrast, other consumers who are relatively insensitive to shopping tiredness may want to take a closer look at each product and spend more time to compare them before making a final purchase decision. Another important factor may be a consumer's involvement in the products. Product involvement refers to the extent to which a consumer perceives a specific product important. Thus, the more involved consumers are in the products such as high cost products, the more serious research about the products are required to make purchase decisions. Conversely, if a consumer intends to purchase a relatively lowinvolvement product, he or she can expect to prefer curated shopping rather than following a complex product search process. Further, considering the curated shopping a relevantly new shopping option, whether consumers had a previous experience of using it may moderate their decision.

While abundant research exists regarding to the factors that influence online consumer's purchase intention, little attention has been paid to the consumer's behavior associated with curated shopping environment. In this study, we try to fill in this gap by investigating how the risk and value of curated shopping perceived by consumers affect their purchase behavior. Moreover, we also examine how individual consumers' personal characteristics and previous experiences influence on their choice of curated shopping. The composition of this study is as follows. In Chapter 2, we review the related studies and develop research models and hypotheses. Chapter 3 presents the data collection procedure and analysis method for empirical analysis as well as the results of the study. Finally, in Chapter 4 we summarize the implications of research findings and future research directions.

\section{Theoretical background and hypotheses}

We established the empirical model of this study and the hypotheses based on the review of a wide range of prior studies. The dependent variable of the study was set as the intention of online consumers to purchase through the curated shopping mall compared 
to the traditional online shopping mall. As the factors affecting the consumer's intention, we investigated the perceived risk of curated shopping, perceived value of curated shopping, and personal characteristics of online consumers including shopping fatigue and product involvement. In Figure 1, the research model of this study is illustrated and the theoretical background and hypotheses are explained below.

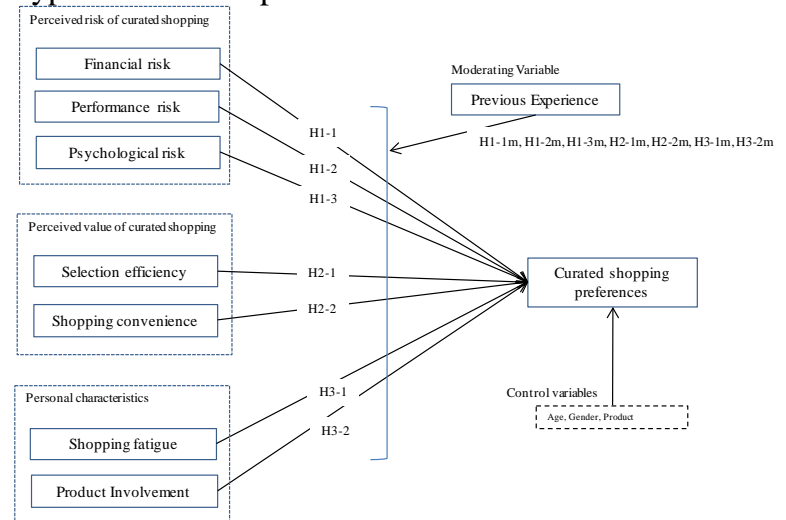

Figure 1. Research model

2.1. Perceived risk and value of curated shopping

The relationship between consumers' perceived risk and the effect of this risk on purchasing has been studied from various perspectives. Bauer's early proposition about perceived risk was that, "consumer behavior involves risk in the sense that any action of a consumer will produce consequences which he cannot anticipate with anything approximating certainty, and some of which at least are likely to be unpleasant" [1:24]. Likewise, Murray and Schlacter [22] explains perceived risk as a function of the uncertainty about the potential outcomes of a behavior and about loss or gain in a transaction. Therefore, the greater the perceived risk, the greater the likelihood that consumers will postpone or abandon their purchases. According to Pavlou and Ge-fen [24], perceived risk expands in online commerce because uncertainty about the lack of knowledge of the seller, quality of goods, delivery and quality assurance is generally higher for online purchases than offline ones.

Because of various reasons that cause the risk perceived by online consumers, researchers have made great efforts to systematically categorize them. While those classifications are slightly different each other, they share several common categories. For example, according to Valla [30], the risk faced by consumers are classified into technical risk, financial risk, shipping risk, service risk, and risk associated with the long-term seller-buyer relationship. In the case of Michell [11], risk is related with losses and it is classified as financial loss, physical loss, temporal loss, and psycho-social loss. In a similar way, Glover and Benbast [10] classify perceived risk as financial risk, time risk, psychological risk, social risk, and physical risk. The current study is in the similar research stream in terms of studying the perceived risk of online consumers. However, in consideration of the unique characteristics of curated shopping, the following three risk factors - financial, performance, and psychological risks were identified as the most relevant to the current research question and redefined in the context of curated shopping.

First, financial risk is defined as a risk that consumers are perceived by the possibility of higher monetary expenditure when they use the curated shopping mall than other traditional shopping malls. For example, the consumer may be concerned that he or she has not been able to sufficiently compare the prices of the product and has paid more than others because of using the curated shopping. Further, some customers may believe that the additional fee might be added to the original product price for the curator's recommendation service $[25,33]$. Second, performance risk implies that the purchased product has a functional error or its quality may be below the level expected by the consumer [14]. When a consumer uses online shopping, the ability to judge product quality may be limited by barriers to touching and trying the product, which generally results in increased performance risk. In the case of curated shopping, the performance risk may be further higher than that of traditional online shopping as the selection process of products will be done by the curator instead of consumers [6, 13]. Lastly, psychological risk implies a concern about the loss of consumer's self-esteem or harmful influence on self-dignity. In this study, psychological risk is defined as the experience of anxiety or discomfort that the products purchased through curated shopping malls will not fit a consumer's taste or value due to the difference of the curator' s selection criteria and the consumer 's preference [16, 17]. Overall, it can be assumed that consumers are less likely to choose the curated shopping when they perceive that risk factors related with curated shopping are high.

[Hypothesis 1] Higher perceived risk of curated shopping is negatively related with the intention to use it.

In Figure 1, $\mathrm{H} 1$ consists of three micro level hypotheses, each illustrates the effect of financial risk (H1-1), psychological risk (H1-2), and psychological risk (H1-3) on the intention to use the curated shopping.

While the curated shopping has various risks inherent in the inability of the consumer to fully reflect 
the purchase intention, it has distinct benefits and value brought by a light and intuitive platform centered on selected products. In this study, we define the value of curated shopping with two categories: the selection efficiency and the purchasing convenience. First, the efficiency of selection means that the curator intervenes in the purchase decision on behalf of the consumer, and through this, the consumer can choose the appropriate product faster and more efficiently. From a consumer's point of view, this efficiency can be related to the trust that the consumers have about the curator's ability. According to Mayer et al. [20], "trust is the willingness of a party to be vulnerable to the actions of another party based on the expectation that the other will perform a action important to the trustor, irrespective of the ability to monitor or control that other party." There are several prior studies dealing with consumers' perceived trust in online shopping [18, $21,23]$ and they showed that online consumers increase their intention to buy when they trust sellers. We assume that this relationship is also valid in curated shopping. If consumers have enough trust on the curator, they may have expectation that the curator will choose the right product although the choice of products may not reflect $100 \%$ personal taste. As a result, the intention to use the curated shopping will increase.

In addition to the selection efficiency, purchasing convenience is another value of curated shopping in terms of saving time, money, and efforts of consumers during online shopping. The curated shopping mall mentioned earlier (e.g., Fab.com, MyHabit.com, and 6PM.com) excludes the excessive product catalog and provides the filtered information on the core products selected by the curator. Therefore, consumers can search for desired products easily and quickly, and it is possible to greatly reduce the effort and time for online shopping. Further, consumers now can subscribe to regular delivery of groceries, household goods, healthy snacks that have been carefully chosen by the curators as well. For example, Blue Apron (blueapron.com) weekly delivers all ingredients necessary to cook an athome meal, already measured and with a recipe. Similarly, NatureBox (naturebox.com) delivers five nutritionist-selected snacks per month. Another example is Birchbox (birchbox.com) that sends subscribers sample-size beauty and skincare products if you pay $\$ 10 /$ month. These subscription businesses can be considered as a special form of curated shopping that particularly focuses on the convenience of online shopping. The differentiated value of the curated shopping, which consumers perceive in general, will positively affect the intention to use the curated shopping
[Hypothesis 2] Higher perceived value of curated shopping is negatively related with the intention to use it.

In Figure 1, H2 consists of two micro level hypotheses, each illustrates the effect of selection efficiency (H2-1) and shopping convenience (H2-2) on the intention to use the curated shopping.

\subsection{Shopping fatigue and product involvement}

One of the important factors affecting the intention to use the curated shopping is the fatigue level of consumers. Most consumers love good deals and they would prefer access to many product information, discounts, and product reviews. But at some point, all the special offers and information become overwhelming, just more confusing background noise because consumers get simply fatigued. Indeed, the consulting company Accenture has conducted a survey of 20,000 smartphone and tablet PC owners around the world for two months starting in November 2012, which found that $41 \%$ of respondents were irritated by too much product information and advertisement. Further, as many online shopping malls have adopted the market place business model, more than one sellers are competing for the same product in the same store (e.g., Amazon marketplace). This results in the increased level of fatigue for consumers as they should not only compare the products but also compare the seller information (e.g., seller specific price and reviews) as well.

Due to those excessive number of products and overflowing information available online, great attention has been drawn to the consumer's shopping fatigue. However, there are still relatively lack of research on this area except few studies that show the negative influence of the irritation and repulsion of the repeated mobile advertisement on the purchase intention [29]. In this study, we define the shopping fatigue as the degree of difficulty and annoyance which consumers perceive when they search for a desired product from too many products listed, with too much information provided, and among too many sellers. Therefore, consumers who have relatively high shopping fatigue will be easily affected by the excessive information, which may ironically increase the demand for the curated shopping. Based on this, the following hypothesis can be suggested.

[Hypothesis 3] Higher shopping fatigue is positively related with the intention to use the curated shopping.

In addition to shopping fatigue, an online consumer can be characterized by their product involvement. The 
product involvement is defined as the level of a consumer's interest in purchasing the product or how committed they are to purchase that product. Depending on their level of product involvement, previous studies showed that consumers follow different processes of making purchase decision [3, 5, 15, 33]. When the involvement level is high, the consumer pursues the related information in depth and becomes more cautious about the decision. In general, product involvement tends to be greater for more expensive goods as wrong decisions could result in great damage. Thus, in this case the process of purchasing products may require considerable research a traditional online shopping is expected to be preferred rather than the curated shopping. On the other hand, if consumers are not greatly involved in products, we can expect them to skip the complicated product search process and prefer the curated shopping. Accordingly, the following hypothesis can be established.

[Hypothesis 4] Higher product involvement is negatively related with the intention to use the curated shopping.

Lastly, we examine the previous experience of using the curated shopping as a moderating variable in the research model. Because the curated shopping is a relevantly new business model and not fully known to many online consumers, we assume that the previous experience can affect the strength of the relationship between the above factors and the intention to use the curated shopping. To indicate moderating effect, the suffix " $\mathrm{m}$ " is added for the names of hypothesis (H11m, H1-2m, H1-3m, H2-1m, H2-2m, H3-1m, and H3$2 \mathrm{~m})$.

\section{Empirical analysis}

\subsection{Data collection and respondents profile}

In this study, we examined the factors influencing consumers' choice of curated shopping as a buying option through empirical analysis. To test the model, we used the online survey method. The questionnaire was divided into three sections. To increase the level of understanding about the curated shopping, the first section compares the existing online shopping mall and curated shopping mall with full descriptions and several screen shots for examples. After then two questions were asked to confirm whether subjects sufficiently understand the difference. The second section consisted of the demographic and personal characteristics of subjects such as shopping fatigue and online shopping preference. In the third section, we have configured the consumer to experience a hypothetical scenario of buying a designated product online. The virtual experience was designed in three different types and the experience of purchasing one of clothing, watch, and cosmetics was randomly assigned at the beginning of the questionnaire using random numbers. By manipulating and controlling through these virtual experiences, we avoid inconsistent questionnaires on various online shopping behaviors, which are difficult to control and generalize for each individual consumer. After finishing the experiment, the subjects were asked to answer the questionnaire regarding to the value and the risk of curated shopping and finally the intention to purchase through the curated shopping mall based on their experiences. Specific questionnaire items are presented in Appendix.

The respondents' profile is summarized in Table 1. Prior to the main survey, we conducted a pilot test using 20 subjects to make sure that the questionnaire items were properly developed to meet the research objectives.

Table 1. Profile of the respondents $(n=255)$

\begin{tabular}{l|lrr}
\hline \multicolumn{1}{c|}{ Attribute } & Value & Frequency & Percentage \\
\hline Gender & Male & 157 & $61.6 \%$ \\
& Female & 98 & $38.4 \%$ \\
\hline Age & Less than 18 & 1 & $0.4 \%$ \\
& $18-25$ & 179 & $70.2 \%$ \\
& $26-35$ & 66 & $25.9 \%$ \\
& $36-45$ & 6 & $2.4 \%$ \\
& Over 45 & 3 & $1.2 \%$ \\
\hline Online Shopping & Less than 6 months & 2 & $0.8 \%$ \\
Period & 6 months - 1 year & 11 & $4.3 \%$ \\
& 1 year - 2 years & 11 & $4.3 \%$ \\
& 2 years - 3 years & 19 & $7.5 \%$ \\
& More than 3 years & 188 & $73.7 \%$ \\
\hline Online Shopping & Never & 12 & $4.7 \%$ \\
Frequency & Less than once every year & 48 & $18.8 \%$ \\
& At least once every month & 140 & $54.9 \%$ \\
& A least once every week & 43 & $16.9 \%$ \\
& Almost everyday & 12 & $4.7 \%$ \\
\hline Online shopping & Almost use offline stores & 32 & $12.5 \%$ \\
Preference & Use online as well but prefer offline & 79 & $31.0 \%$ \\
& stores & 67 & $26.3 \%$ \\
& Use both similarly & 67 & $24.7 \%$ \\
& Use offline as well but prefer online & 63 & \\
& stores & & \\
& Almost use online stores & 14 & $5.5 \%$ \\
\hline Curated shopping & I have used curated shopping & 84 & $32.9 \%$ \\
Experience & & & \\
\hline
\end{tabular}

We examined the responses to the preliminary instrument for consistency and revised the items in the questionnaire, such that there are no redundant items; all items are phrased clearly and concisely. Then, we surveyed a total of 325 students to access a suitable sample of consumers who experienced online shopping. To minimize the problem of the representative sample composition, 82 students of the Executive MBA program and working adult program students were included in the survey pool. Among them, 257 respondents answered the questionnaire (response rate $71.8 \%$ ) and they were given some extra credits for the course. After eliminating observations with missing and unusable data, we used 255 observations to test the model and hypotheses. The participants were $61.6 \%$ male and $38.4 \%$ female, and 
most of the respondents were aged between their 20s and 30s. Although student participants may not fully represent the online shopper population, many previous studies [2, 6, 8, 18, 19] showed that college students are a good surrogate for online consumers. Indeed, the data collected in the present study also indicated that the participants are active online consumers: over $70 \%$ of the respondents reported that they had shopped online more than three years and do online shopping at least once a month. Moreover, 32.9\% of respondents said they had experience with curated shopping, which is the focus of this study, showing that curated shopping has become popular in the last 1-2 years.

One interesting fact we found from online shopping preference is that the rapid propagation of online shopping does not necessarily mean complete replacement of the offline market. In Table 1, 30.7\% of respondents would like to use online store $(24.7 \%$ prefer online and 5.5\% use almost online stores), but still higher percentage of $43.5 \%$ respondents answered that they would like to use offline store (31.0\% prefer offline and $12.5 \%$ use almost offline). Although there is no direct connection with this study, this implies that the importance of $\mathrm{O} 2 \mathrm{O}$ (Online to offline, or Offline to online) market that is receiving much attention recently as an effective linkage between offline and online markets.

We used Partial Least Square method for Structural Equation Modeling (PLS-SEM) to analyze the data collected and test the research model. PLSSEM is a statistical technique that incorporates factor analysis (using a measurement model) and path analysis (using a structural model) [26, 31]. The advantages of PLS-SEM compared to other statistical techniques include more flexible assumptions (e.g., partial allowance of multicollinearity) and less measurement error with confirmatory factor analysis (CFA) enabled by multiple indicators per construct. The number of samples used in PLS-SEM analysis needs to be at least 10 times the maximum number of measurement variables [9]. In this study, we have maximum three variables for measurement, therefore the sample size of 257 ( $>$ 30) is sufficient. To test the model, we have used R with PLS-PM package [28], which is particularly powerful for comparing groups. In particular, we compare one group with previous experiences of using curated shopping and the other with no experience.

\subsection{Measurement model assessment}

The internal consistency (reliability) statistics were assessed by Cronbach's alpha and composite reliability (Dillon Goldstein's Rho), and the results are summarized in Table 2.
Table 2. Reliability and Convergent Validity Assessment of the Measurement Model

\begin{tabular}{l|ccccc}
\hline & \# of items & $\begin{array}{c}\text { Cronbach's } \\
\text { Alpha }\end{array}$ & Reliability & AVE & $\begin{array}{c}\text { Latent } \\
\text { variable } \\
\text { Index }\end{array}$ \\
\hline Financial risk & 3 & 0.75 & 0.86 & 0.66 & 3.77 \\
Performance risk & 3 & 0.79 & 0.88 & 0.70 & 3.26 \\
Psychological risk & 3 & 0.84 & 0.90 & 0.73 & 3.18 \\
Selection efficiency & 3 & 0.79 & 0.88 & 0.70 & 3.39 \\
Purchasing convenience & 3 & 0.87 & 0.92 & 0.79 & 3.51 \\
Shopping fatigue & 3 & 0.75 & 0.86 & 0.67 & 3.08 \\
Product Involvement & 2 & 0.75 & 0.89 & 0.80 & 3.48 \\
Intension to use the curated shopping & 3 & 0.84 & 0.90 & 0.75 & 3.14 \\
\hline
\end{tabular}

All Cronbach's Alpha and composite reliability values exceeded the recommended reliability threshold of 0.7 [7]. Therefore, all questionnaire items were deemed reliable. In addition, we tested the convergent validity by examining the average variance extracted (AVE), which measures the percentage of the variance of the measurement items that can be accounted for the constructs relative to the measurement error. Table 2 illustrates that for each construct, the AVE value was greater than the cut-off value of 0.5 [32]. The mean value was taken considering the weight of the measurement items (Latent Variable Index).

\section{Table 3. Discriminant Validity Assessment of} the Measurement Model

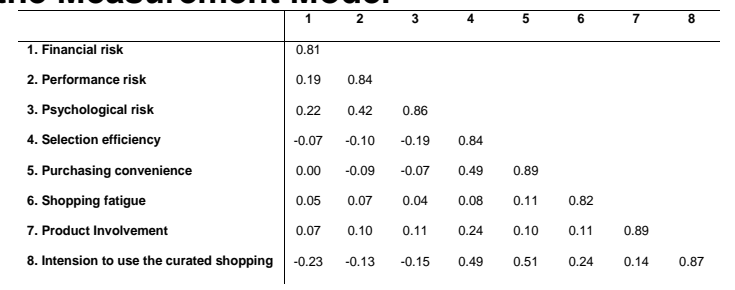

Note: The principal diagonal (inboldface) of the intercorrelation matrix represents the square root of the average variance extracted (AVE) per construct.

Further, we tested the discriminant validity by examining whether a latent variable better explains the variance of its own indicators than the variance of other latent variables. To validate this, we compared the square root of AVE for each construct with its cross-correlation with other constructs. The results supported the discriminant validity of our constructs in that in all cases, the diagonal elements in the matrix (i.e., the square root of AVE) were higher than the offdiagonal elements in the corresponding rows and columns, as shown in Table 3.

\subsection{Structural model assessment I: unmoderated model}


The assessment of the structural model includes estimation of the path coefficients and R2 values. In this study, the R2 value of intention to use the curated shopping is $43.7 \%$, which shows very high explanatory power. The path coefficients are summarized in Table 4.

Table 4. Summary of the Results of the Unmoderated Model

\begin{tabular}{|c|l|c|c|c|c|l}
\hline $\begin{array}{c}\text { Hypothe } \\
\text { ses }\end{array}$ & \multicolumn{1}{|c|}{ Effect } & $\begin{array}{c}\text { Coeffi } \\
\text { cient }\end{array}$ & S.E. & t-stat & $\begin{array}{c}\text { p- } \\
\text { value }\end{array}$ & Conclusion \\
\hline H1-1 & Financial risk $\rightarrow$ Use the created shopping & -0.21 & 0.05 & -4.06 & 0.00 & Supported \\
\hline H1-2 & Performance risk $\rightarrow$ Use the created shopping & -0.03 & 0.05 & -0.68 & 0.50 & $\begin{array}{l}\text { Not } \\
\text { supported }\end{array}$ \\
\hline H1-3 & Psychological risk $\rightarrow$ Use the created shopping & -0.03 & 0.06 & -0.62 & 0.54 & $\begin{array}{l}\text { Not } \\
\text { supported }\end{array}$ \\
\hline H2-1 & $\begin{array}{l}\text { Selection efficiency } \rightarrow \text { Use the created } \\
\text { shopping }\end{array}$ & 0.27 & 0.06 & 4.71 & 0.00 & Supported \\
\hline H2-2 & $\begin{array}{l}\text { Purchasing convenience } \rightarrow \text { Use the created } \\
\text { shopping }\end{array}$ & 0.34 & 0.06 & 6.02 & 0.00 & Supported \\
\hline H3 & Shopping fatigue $\rightarrow$ Use the created shopping & 0.18 & 0.05 & $\mathbf{3 . 8 1}$ & $\mathbf{0 . 0 0}$ & Supported \\
\hline H4 & $\begin{array}{l}\text { Product Involvement } \rightarrow \text { Use the created } \\
\text { shopping }\end{array}$ & 0.02 & 0.05 & 0.43 & 0.67 & $\begin{array}{l}\text { Not } \\
\text { supported }\end{array}$ \\
\hline Control & Age $\rightarrow$ Use the created shopping & 0.03 & 0.05 & 0.55 & 0.58 & \\
\cline { 2 - 7 } & Gender (female) $\rightarrow$ Use the created shopping & 0.10 & 0.05 & 2.11 & 0.04 & \\
\cline { 2 - 7 } & Product type (watch) & 0.01 & 0.06 & 0.14 & 0.89 & \\
\cline { 2 - 7 } & Product type (clothe) & -0.02 & 0.06 & -0.46 & 0.64 & \\
\hline
\end{tabular}

First, Hypothesis 1 on the effect of perceived risk was partially accepted. Specifically, performance risk (H1-2) and psychological (H1-3) risk did not show any significant influence, but financial risk (H1-1) showed a negative (-) influence on the intention to use the curated shopping $(\beta=-0.20, \mathrm{t}=-4.06, \mathrm{p}<0.01)$. On the other hand, Hypothesis 2 on the influence of the perceived value of curated shopping was fully accepted. In other words, both selection efficiency (H2-1: $\beta=0.27, \mathrm{t}=4.71, \mathrm{p}<0.01)$ and purchasing convenience (H2-2: $\beta=0.34, \mathrm{t}=6.02, \mathrm{p}<0.01$ ) showed a significant positive $(+)$ relationship with the intention to use the curated shopping. Further, Hypothesis 3 that the shopping fatigue will increase $(+)$ the intention to use the curated shopping was also adopted at $1 \%$ significance level $(\beta=0.19, \mathrm{t}=3.81$, $\mathrm{p}$ $<0.01)$. However, Hypothesis 4, which examined the effect of consumer involvement on purchase intention, was rejected because it was not statistically significant $(\beta=0.02, t=0.43, p=0.67)$.

In addition, control variables such as differences in product types, gender, and age were included in the research model. As the product type changed, it was assumed that the purchasing intention would be influenced and controlled, but no statistically significant difference was found. On the other hand, there was a difference in intention to use the curated shopping according to gender. In the $5 \%$ level of significance, women were more likely to purchase through the curated shopping than men $(\beta=0.10, t=$ 2.11, $\mathrm{p}=0.04)$.

\subsection{Structural model assessment II: moderated model}

To measure the moderating effect of a consumer's experience to use the curated shopping, we conducted additional assessment. There are several different approaches to examine the moderating effect in PLSSEM such as two-stage path modeling approach, twostage regression approach, categorical variable approach, and group comparison [28]. In this study, we adopted group comparison approach using a t-test based on permutation resampling. The result is summarized in Table 5.

We found three factors (financial risk, selection efficiency, and purchasing convenience) that significantly affect intention to use the curated shopping and at the same time, the differences between the two groups are also significant. First, the financial risk had a much higher negative impact on purchase intention in the experienced group $(\beta=-0.36)$ than the inexperienced group $(\beta=-0.14)$. On the other hand, in the case of selection efficiency, which is a positive factor, the influence was larger in the experienced group $(\beta=0.48)$ than the inexperienced $(\beta=0.19)$. In terms of purchasing convenience, the inexperienced group $(\beta=0.39)$ is more sensitive than the experienced group ( $\beta=0.20)$. One interesting point is that the gender of the control variable indicates that the inexperienced female consumer $(\beta=0.15)$ is likely to use curated shopping but inexperienced group does not show the gender difference.

Table 5. Summary of the Results of the Moderated Model: Two Group Comparison

\begin{tabular}{|c|l|c|c|c|c|}
\hline $\begin{array}{c}\text { Hypot } \\
\text { hesis }\end{array}$ & Effect & $\begin{array}{c}\text { All } \\
\text { (p-value) }\end{array}$ & $\begin{array}{c}\text { Inexperien } \\
\text {-ed } \\
\text {-value) }\end{array}$ & $\begin{array}{c}\text { Experienc } \\
\text { ed } \\
\text { (-value) }\end{array}$ & $\begin{array}{c}\text { Group } \\
\text { Difference (p- } \\
\text { value) }\end{array}$ \\
\hline H1-1 & Financial risk $\rightarrow$ Use the created shopping & -0.21 & -0.14 & -0.36 & Yes \\
& $(0.00)$ & $(0.03)$ & $(0.00)$ & $(0.04)$ \\
\hline H1-2 & Performance risk $\rightarrow$ Use the created shopping & -0.03 & -0.09 & 0.08 & No \\
& & $(0.50)$ & $(0.18)$ & $(0.31)$ & $(0.05)$ \\
\hline H1-3 & Psychological risk $\rightarrow$ Use the created shopping & -0.03 & -0.05 & 0.00 & No \\
& & $(0.54)$ & $(0.45)$ & $(0.95)$ & $(0.35)$ \\
\hline H2-1 & Selection efficiency $\rightarrow$ Use the created & 0.27 & 0.19 & 0.48 & Yes \\
& shopping & $(0.00)$ & $(0.01)$ & $(0.00)$ & $(0.01)$ \\
\hline H2-2 & Purchasing convenience $\rightarrow$ Use the created & 0.34 & 0.39 & 0.20 & Yes \\
& shopping & $(0.00)$ & $(0.00)$ & $(0.03)$ & $(0.06)$ \\
\hline H3 & Shopping fatigue $\rightarrow$ Use the created shopping & 0.18 & 0.17 & 0.26 & No \\
& & $(0.00)$ & $(0.01)$ & $(0.00)$ & $(0.14)$ \\
\hline H4 & Product Involvement $\rightarrow$ Use the created & 0.02 & 0.07 & -0.04 & No \\
& shopping & $(0.67)$ & $(0.31)$ & $(0.62)$ & $(0.21)$ \\
\hline Contr & Age $\rightarrow$ Use the created shopping & 0.03 & 0.07 & -0.14 & Yes \\
ol & & $(0.58)$ & $(0.30)$ & $(0.10)$ & $(0.01)$ \\
\cline { 2 - 7 } & Gender (female) $\rightarrow$ Use the created shopping & 0.10 & 0.15 & 0.01 & Yes \\
& & $(0.04)$ & $(0.02)$ & $(0.88)$ & $(0.08)$ \\
\cline { 2 - 7 } & Product type (watch) & 0.01 & -0.04 & 0.03 & No \\
& & $(0.89)$ & $(0.54)$ & $(0.72)$ & $(0.26)$ \\
\cline { 2 - 7 } & Product type (clothe) & -0.02 & -0.03 & -0.08 & No \\
& & $(0.64)$ & $(0.67)$ & $(0.40)$ & $(0.37)$ \\
\hline
\end{tabular}

Note:

- The subjects were divided into two groups: experienced consumers (84 subjects) and inexperienced consumers (171 subjects).

- The significant path coefficients are bold-faced and the meaningful group differences are highlighted. 


\section{Conclusion}

\subsection{Results and implications}

The increased online product variety ironically offset the previous advantage of low cost online shopping by requiring consumers to spend excessive time and efforts for searching the relevant information. Under this stressful shopping environment, we have investigated various factors that can affect the online consumer's decision to use curated shopping. The academic and practical implications of these findings can be summarized as follows.

First, the study has extended the scope of the research on purchase intention of online consumers by considering a new phenomenon called curated shopping. In particular, we could reexamine various factors such as perceived risks and benefits of online shopping, which have been studied in the past to find the influence on purchasing intention, from a new perspective of curated shopping. As a result, it was confirmed that the convenience and efficiency of curated shopping are critical factors to increase purchasing intention through curated shopping. On the contrary, the financial risk perceived by consumers was revealed to be an important negative factor for the usage of curated shopping.

Second, we have carried out experimental study on the new factors that are getting more attention recently. We found that the shopping fatigue, perceived by consumers due to the excessive amount of information online, could increase the intention of using curated shopping. Therefore, we believe that this study has provided an opening to further research on the effect of shopping fatigue on consumer behavior in the future.

On the other hand, we can find several managerial implications from this study as well. First, we confirmed the importance of customized shopping services, which consider a consumer's personal preferences and characteristics. With the overflowing shopping-related information, many online stores recognize the importance of curating service and start to implement it as a business strategy. However, managers should not simply predict that curated shopping will become more prevalent and recklessly increase the number of curated shopping malls. This approach may lead to no gain but unnecessary competition with existing online stores. Instead, the results of this study suggest that there is a need to selectively offer curated shopping, considering the degree of shopping fatigue, risk and value perception of each consumer in advance. For example, the online shopping mall may be able to recommend curated shopping for the consumers who feel easily fatigued with shopping information but can provide traditional shopping for other consumers who are less fatigued and would like to search all the products by themselves. Indeed, some top online shopping such as Amazon.com started to offer their traditional shopping malls with a few affiliate curated shopping malls such as A9.com and MyHabit.com together.

Second, it is necessary for managers to realize the importance of financial risk about curated shopping and make strategic response against it. In Table 2, the average scale of financial risk is 3.77 (5-point scale) that is higher than both the performance risk (3.26) and psychological risk (3.18), which implies a lot of consumers are more sensitive to price than other factors. These consumers are likely to think that they are not participating in the price comparison directly because of the use of curated shopping, and as a result they will believe the possibility of financial loss is high. This concern leads to a negative effect on a consumer's intention to use curated shopping. Therefore, it is critical for the manager to provide an assurance policy that can reduce the concern about the possibility of financial loss of using curated shopping, and actively promote this policy. For example, the price information in other general stores can be presented in parallel for comparison, or the introduction of the after-sales price matching system can be another example. This kind of assurance policy aiming at resolving the financial risk of curated shopping will lead to the enhancement of consumer trust, strengthening the customer relationship and ultimately contributing to the increase in sales.

Third, managers may differentiate curated shopping from existing online shopping in few different ways. For example, managers must implement a strategy that can enhance the efficiency and convenience of curated shopping, which consumers recognize as the key value of using it. In addition, managers need to carefully choose a well-defined target market that consists of consumers who are experiencing particularly high shopping fatigue as they are more likely to use curated shopping. Moreover, considering the result that women are more likely to use curated shopping, it is necessary to pursue a more aggressive marketing strategy targeting women customers.

Finally, given the results of two group comparison assessment, it is necessary to develop differentiated strategies between consumers with experience in curated shopping and consumers who do not have experience. For example, the inexperienced consumer group is more sensitive in the effect of financial risk and the value of selection efficiency, however; the experienced consumer group shows higher sensitivity in purchasing convenience. Therefore, it is important for managers to find new consumers but at the same 
time, it is essential to enhance purchasing convenience for existing curated shopping consumers. Similarly, the inexperienced female consumer is more likely to use curation shopping, which suggests that managers can focus more on new woman consumers to expand their market size.

\subsection{Limitations}

This study has the following limitations and it will serve as a guideline for future direction of research. First, the current study has been conducted at the adoption and rapid growth stage of curated shopping and it is necessary to conduct a longitudinal comparative study in the future when it becomes mature stage. As curated shopping becomes more prevalent in the future, not only the perceived risks of consumers may be reduced but also the benefits expected from curated shopping will be diversified with the introduction of new shopping techniques. As a result, the impact of individual factors on purchasing decisions is also expected to change over time. Second, in the follow-up study, additional factors besides the factors investigated in this study can be considered. For example, from a consumer's standpoint, curators and sellers are separate entities, so trust in curators and trust in commerce sellers can be divided into individual factors. In addition, price, quality of product information, ease of use, and system stability can be considered as additional seller characteristics. Third, we previously pointed out the problem about the representativeness of questionnaire using students as subjects. In addition, there is a limit to the survey because only $32.9 \%$ of the respondents responded that they have experienced real curated shopping, while the rest of them had only hypothetical indirect experience during the survey. In the future, it is necessary to generalize research results by reexamining research models and hypotheses through empirical studies on more general consumers.

\section{References}

[1] Bauer, R.A. Consumer behavior as risk taking. American Marketing Association, Chicago, IL, 1960.

[2] Bhatnagar, A., Misra, S., and Rao, H.R. On Risk, Convenience and Internet Shopping Behavior. Communications of the ACM 43, 11 (2000), 98-108.

[3] Browne, B.A. and K., D.O. Conceptualizing Selfmonitoring: Links to Materialism and Product Involvement. Journal of Consumer Marketing 14, 31-44. (1997), 31-44.
[4] CEO.com. Infographic: A CEO’s Guide To Pinterest. (2012).

[5] Dholakia, U.M. A motivational process model of product involvement and consumer risk perception. European Journal of Marketing 35, 11/12 (2001), 1340-1360.

[6] Featherman, M.S. and Pavlou, P.A. Predicting e-services adoption: a perceived risk facets perspective. International Journal of Human-Computer Studies 59, 4 (2003), 451-474.

[7] Fornell, C.R. and Larcker, D.F. Evaluating structural equation models with unobservable variables and measurement error. Journal of Marketing Research 18, 1 (1981), 39-50.

[8] Gefen, D. E-commerce: the Role of Familiarity and Trust. Omega: The International Journal of management Science 28, 6 (2000), 725-737.

[9] Gefen, D., Straub, D., and Boudreau, M.-C. Structural equation modeling and regression: Guidelines for research practice. Communications of the association for information systems 4, 1 (2000), 7.

[10] Glover, S. and Benbasat, I. A Comprehensive Model of Perceived Risk of E-Commerce Transactions. International Journal of Electronic Commerce 15, 2 (2011), 47-78.

[11] Hassan, A.M., Kunz, M.B., Pearson, A.W., and Mohamed, A. Conceptualization and Measurement of Perceived Risk in Online Shopping. Marketing Management Journal 16, 1 (2006), 138-147.

[12] Hong, I. and Cha, H. The Mediating Role of Consumer Trust in an Online Merchant in Predicting Purchase Intention. International Journal of Information Management 33, (2013), 927-939.

[13] Hong, I.B., Kim, T.H., and Cha, H.S. The Mediating Role of Perceived Risk in the Relationships Between Enduring Product Involvement and Trust Expectation. Asia Pacific Journal of Information Systems 23, 4 (2013), 103128.

[14] Horton, R.L. The structure of perceived risk: Some further progress. Journal of the Academy of Marketing Science 4, 4 (1976), 694-706.

[15] Houston, M.J. and R., M.L. Conceptual and methodological perspectives in involvement. (1978), 184187.

[16] Hwang, I.C., Hwang, J.H., and Jung, M.S. A Study on the Perceived Risk and Risk Reduction Behavior in Electronic Commerce. The Journal of Information Strategy 4, 1 (2001), 223-244.

[17] Jacoby, J. and Kaplan, L.B. The Components of Perceived Risk. (1972), 382-393. 
[18] Jarvenpaa, S.L., Tractinsky, J., and Vitale, M. Consumer Trust in an Internet Store. Information Technology and Management 1, (2000), 45-71.

[19] Lee, M. and Turban, E. A Trust Model for Consumer Internet Shopping," Vol. 6, No. 1, , pp. . International Journal of Electronic Commerce 6, 1 (2001), 75-91.

[20] Mayer, R.C., Davis, J.H., and Schoorman, F.D. An Integrative Model of Organizational Trust. Academy of Management Review 20, 3 (1995), 709-734.

[21] McKnight, D.H. and Chervany, N.L. What trust means in e-commerce customer relationships: an interdisciplinary conceptual typology. International Journal of Electronic Commerce 6, 2 (2002), 35-59.

[22] Murray, K.B. and Schlacter, J.L. The impact of services versus goods on consumers' assessment of perceived risk and variability. Journal of the Academy of Marketing Science 18, 1 (1990), 51-65.

[23] Pavlou, P.A. Consumer Acceptance of Electronic Commerce: Integrating Trust and Risk with the Technology Acceptance Model. International Journal of Electronic Commerce 7, 3 (2003), 69-103.

[24] Pavlou, P.A. and Gefen, D. Building Effective Online Marketplaces with Institution-Based Trust. Information Systems Research 15, 1 (2004), 37-59.

[25] Petty, R.E. and Cacioppo, J.T. Involvement and persuasion: Tradition versus integration. Psychological Bulletin 107, 3 (1990), 367-374.
[26] Qureshi, I. and Compeau, D. Assessing Between-Group Differences in Information Systems Research: A Comparison of Covariance-and Componet-based SEM. MIS Quarterly 33, 1 (2009), 197-214.

[27] Rosenbaum, S. Curation Nation: How to Win in a World Where Consumers are Creators. McGraw-Hill Professional Publishing, 2011.

[28] Sanchez, G. PLS path modeling with R. Berkeley: Trowchez Editions, (2013).

[29] Tsang, M.M., Ho, S.-C., and Liang, T.-P. Consumer Attitudes Toward Mobile Advertising: An Empirical Study. Int. J. Electron. Commerce 8, 3 (2004), 65-78.

[30] Valla, J.P. The Concept of Risk in Industrial Buying Behaviour, Workshop on Organizational Buying Behaviour. (1982), 9-10.

[31] Wetzels, M., Odekerken-Schroder, G., and Oppean, C. van. Using PLS Path Modeling for Assessing Hierarchical Construct Models: Guidelines and Empirical Illustration. MIS Quarterly 33, 1 (2009), 177-195.

[32] Yoo, Y. and Alavi, M. Media and group cohesion: relative influences on social present, task participation, and group consensus. MIS Quarterly 25, 3 (2001), 371-390.

[33] Zaichkowsky, J.L. The personal involvement inventory: Reduction, revision, and application to advertising. Journal of advertising, (1994), 59-70. 